\title{
EFEITO DO PROCESSAMENTO SOBRE OS NÍVEIS DE COLESTEROL E 7-CETOCOLESTEROL EM CAMARÃO-ROSA ${ }^{1}$
}

\author{
Andréa Figueiredo Procópio de MOURA², Alfredo TENUTA-FILHO ${ }^{2, *}$
}

\begin{abstract}
RESUMO
A oxidação do colesterol leva à formação de óxidos biologicamente ativos, capazes de desencadear processos citotóxicos, aterogênicos, mutagênicos e cancerigenos. Durante o processamento, os alimentos são expostos, além do calor, ao oxigênio e a outros fatores desencadeadores da oxidação lipídica, inclusive do colesterol. Os crustáceos, além de possuírem níveis elevados de colesterol, apresentam em sua fração lipídica ácidos graxos com alto grau de insaturação, o que favorece a oxidação do referido esterol. O 7-cetocolesterol tem sido utilizado como indicador da oxidação do colesterol, por ser o óxido formado nos estágios iniciais e em maior quantidade que os demais. O objetivo deste trabalho foi avaliar o efeito do cozimento e da fritura sobre a oxidação do colesterol em camarão-rosa (Penaeus brasiliensis e Penaeus paulensis). O processamento do camarão-rosa, de um modo geral, levou à diminuição das concentrações de colesterol e 7-cetocolesterol livres. A redução observada foi bem maior na fritura do que no cozimento, e mais acentuada para o 7cetocolesterol. Enquanto os niveis de colesterol foram 10,7 e 24,7\% menores, a diminuição do 7 -cetocolesterol atingiu 41,5 e $61 \%$ no camarão cozido e frito, respectivamente, em relação ao controle. A redução de colesterol e 7 -cetocolesterol livres em camarão-rosa processado foi relacionada com a eluição destes compostos nos meios de processamento, água de cozimento e óleo de fritura.

Palavras-chave: colesterol; oxidação; 7-cetocolesterol; camarão; cozimento; fritura.
\end{abstract}

\section{SUMMARY}

EFFECTS OF PROCESSING ON FREE CHOLESTEROL AND 7-KETOCHOLESTEROL CONCENTRATIONS IN PINK-SHRIMP. Cholesterol oxidation results in the production of oxides that exert a wide range of biological activities such as atherosclerosis, mutagenesis, carcinogenesis and citotoxicity. During cooking foods are exposed to oxygen, heat and other factors that can promote lipid oxidation, including cholesterol oxidation. Because of the presence of polyunsaturated fatty acids and the high levels of cholesterol crustaceous have a great potential for oxide production. 7-ketocholesterol has been used as a "tracer" of the degree of cholesterol oxidation, due to its fast and continuous formation and thus relatively high amounts with respect to the other oxidation products. The objective of this work was to evaluate the effects of boiling and deep-frying on the cholesterol oxidation in pink-shrimp (Penaeus brasiliensis and Penaeus paulensis). Cooking of pink-shrimp, in general, decreased both free cholesterol and 7-ketocholesterol concentrations. Such decrease was higher after frying than after boiling and was more pronounced for 7-ketocholesterol. While the cholesterol concentrations were 10.7 and $24.7 \%$ lower, the decrease of 7 -ketocholesterol concentrations was 41.5 and $61 \%$ in boiled and fried shrimp, respectively. The reduction of free cholesterol and 7-ketocholesterol concentrations in processed pink-shrimp was related to elution of these compounds by the cooking medium, i.e. water in boiling and oil in frying.

Keywords: cholesterol; oxidation; 7-ketocholesterol; shrimp; boiling; frying.

\section{1 - INTRODUÇÃO}

O colesterol encontra-se distribuído nos tecidos animais como principal esterol. Desempenha funções estruturais e funcionais nas membranas celulares, sendo o precursor dos ácidos biliares e hormônios esteróides. Como lipide insaturado, está sujeito à oxidação, gerando óxidos biologicamente ativos. Existem evidências da participação de óxidos de colesterol em vários processos caracterizando-os como citotóxicos [24, 25], mutagênicos [34], aterogênicos [30] e cancerígenos [11].

Os alimentos de origem animal são a rigor as principais fontes de colesterol na dieta. O colesterol encontrase no alimento intimamente associado a outros lipides. A oxidação desses lípides pode levar à oxidação do colesterol, principalmente se estiverem presentes ácidos graxos polinsaturados, que são mais facilmente oxidáveis $[13,14,36]$. A presença de oxigênio, calor, radiação e metais de transição desencadeia o processo oxidativo $[14,28]$. Durante o processamento os alimentos são expostos a vários destes fatores.
Dentre os produtos da oxidação do colesterol, o 7-cetocolesterol tem sido utilizado como indicador da oxidação do colesterol por ser produzido em maior quantidade e nos estágios iniciais do processo oxidativo [29,32, 38, 39].

Estudos que avaliaram o efeito do processamento térmico sobre a formação dos óxidos de colesterol em alimentos sugerem que o tempo e a temperatura são fatores determinantes neste processo, influenciando diretamente a taxa de oxidação [12, 21, 26, 31].

Embora possuam atributos adequados para a formação de óxidos de colesterol, os produtos marinhos têm sido pouco estudados neste sentido. Moluscos e crustáceos apresentam niveis relativamente elevados de colesterol, além de possuírem alta proporção de ácidos graxos polinsaturados em sua fração lipídica [10]. No camarão, em particular, têm sido constatado teores variando entre 90 e $200 \mathrm{mg} / 100 \mathrm{~g}[10,15,16,17]$.

O objetivo do presente trabalho foi avaliar o efeito do cozimento e da fritura sobre o colesterol e o 7-cetocolesterol livres em camarão-rosa.

\footnotetext{
${ }^{1}$ Recebido para publicação em 24/11/00. Aceito para publicação em 07/01/02.

${ }^{2}$ Departamento de Alimentos e Nutrição Experimental - Faculdade de Ciências Farmacêuticas/USP - Av. Prof. Lineu Prestes, 580, Bloco 14 - Butantã - São Paulo - SP - CEP 05508-900

* A quem a correspondência deve ser enviada.
} 


\section{2 - MATERIAL E MÉTODOS}

\section{1 - Material}

O Penaeus brasiliensis e Penaeus paulensis, conhecidos e comercializados como camarão-rosa, foram analisados indistintamente no presente trabalho. As amostras foram adquiridas em peixarias, feiras-livre e supermercados do município de São Paulo - SP, entre julho e setembro de 1999, com tamanhos e pesos variando entre 13 e $15 \mathrm{~cm}$ e 30 e $33 \mathrm{~g}$, respectivamente. Foram analisados 4 lotes de $1 \mathrm{Kg}$ cada, procedentes do litoral paulista.

As amostras frescas (controle) e processadas foram empregadas sem o exoesqueleto, cefalotórax e intestino. Para as análises, essas amostras foram previamente trituradas e homogeneizadas em homogeneizador Tecnal modelo TE102.

\section{2 - Processamentos}

As amostras foram processadas sem o emprego de condimentos. O cozimento foi conduzido em água destilada fervente, por 4 minutos, e a fritura realizada em óleo de soja, a $140^{\circ} \mathrm{C}$, por 3 minutos, em fritadeira elétrica (Moulinex T49) com tempo e temperatura programáveis. Foi observada ao final dos processamentos uma temperatura interna do produto entre 75 e $80^{\circ} \mathrm{C}$, medida através de termômetro comum. A água usada no cozimento e o óleo empregado na fritura foram analisados para confirmação da presença de colesterol e 7-cetocolesterol.

\section{3 - Umidade e lipides totais}

A umidade foi determinada segundo a AOAC [2] e o teor lipídico total segundo BLIGH \& DYER [3].

\section{4 - Extração e quantificação de colesterol e 7- cetocolesterol livres}

\subsection{1 - Extração}

Foi utilizada a técnica proposta por CSALLANY et al. [6], adaptada de FOLCH, LESS, STANLEY [8], cujo procedimento iniciou-se com a pesagem da amostra $(0,5 \mathrm{~g})$ e adição de $20 \mathrm{~mL}$ da solução de clorofórmiometanol (2:1), seguida da homogeneização em velocidade média (Homogeneizador Tecnal modelo TE102) por cerca de $1 \mathrm{~min}$. O homogenato foi transferido para um funil de separação e lavado duas vezes com 50mL de água destilada. As águas de lavagem foram combinadas e extraídas por duas vezes consecutivas com $25 \mathrm{~mL}$ de clorofórmio: metanol (2:1). As amostras foram centrifugadas a $4000 \mathrm{xg}$, por 15 minutos, a $22^{\circ} \mathrm{C}$ (centrífuga Sorvall Superspeed RC2-B). A camada de clorofórmio foi removida e desidratada, por filtração em sulfato de sódio anidro. Depois da filtração, o solvente foi concentrado em roto-evaporador e evaporado sob fluxo de nitrogênio. O resíduo foi dissolvido com $3 \mathrm{~mL}$ de fase móvel. Seguiu-se a filtração em membrana, com poro de $0,45 \mu \mathrm{m}$ (Unidade Filtrante HV Millex - Millipore).
Após a filtração, a amostra foi concentrada sob fluxo de nitrogênio, reduzindo seu volume para $2 \mathrm{~mL}$. Aliquotas de $30 \mu \mathrm{L}$ foram injetadas automaticamente no cromatógrafo.

\subsection{2 - Quantificação}

O colesterol e o 7-cetocolesterol foram determinados utilizando um sistema de HPLC Shimadzu, modelo SCL-10A ${ }_{V P}$, equipado com detetores de fotodiodos SPD${\mathrm{M} 10 \mathrm{~A}_{V P} \text {, sistema de bombas LC-10AD }}_{V P}$ e injetor automático de amostras SIL-10AD ${ }_{V P}$. Foi empregado o método de CSALLANY et al. [6], utilizando uma coluna de sílica, $5 \mu$-Porasil $30 \times 0,39 \mathrm{~cm}$ (Waters Associates), diâmetro de poro de $10 \mu \mathrm{m}$, em fase normal. A fase móvel foi hexano-isopropanol 97:3 (v/v) e as leituras do colesterol e 7 -cetocolesterol foram realizadas a $206 \mathrm{~nm}$ e a $233 \mathrm{~nm}$, respectivamente (Figura 1 ).

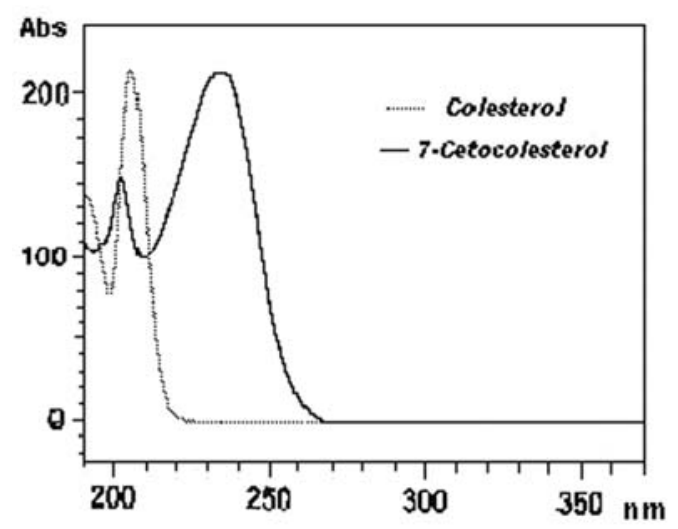

FIGURA 1. Espectro de absorção ultravioleta do colesterol e do 7-cetocolesterol em hexano: isopropanol (97:3).

A identificação dos picos de colesterol e 7-cetocolesterol foi realizada pela comparação dos tempos de retenção da amostra em relação aos padrões correspondentes. A quantificação foi feita por padronização externa, pela medida da área do pico, sendo a curva-padrão do colesterol construída entre 10 e $50 \mu \mathrm{g}$ e a do 7-cetocolesterol de 0,1 a 0,5 $\mu \mathrm{g}\left(\mathrm{r}^{2}=0,999\right)$.

Os limites de detecção [18] correspondentes foram de $1 \times 10^{-9} \mathrm{~g}$. A recuperação do colesterol foi de 99,9\% e a do 7 -cetocolesterol de 93,5\%.

\section{3 - RESULTADOS E DISCUSSÃO}

\section{1 - Lipides totais}

O camarão-rosa fresco apresentou um teor lipídico médio de 1,13 \pm 0,09g/100g, não sendo observada diferença significativa em relação ao do camarão cozido. Já, quando submetido à fritura, o camarão teve seu teor lipídico significativamente aumentado em 3 vezes ( $\mathrm{Ta}$ bela 1). 
TABELA 1. Umidade e lípides totais do camarão-rosa fresco, cozido e frito (g/100g amostra) (a).

\begin{tabular}{lccc}
\hline Amostra & Umidade & Lípides em Base Úmida & Lípides em Base Seca \\
\hline Fresca & $78,2 \pm 1,9$ & $1,13 \pm 0,09$ & $4,86 \pm 0,38^{\mathrm{a}}$ \\
Cozida & $73,7 \pm 1,6$ & $1,33 \pm 0,04$ & $5,22 \pm 0,60^{\mathrm{a}}$ \\
Frita & $62,5 \pm 1,7 \mathrm{c}$ & $4,92 \pm 0,45$ & $14,18 \pm 1,63 \mathrm{~b}$ \\
\hline
\end{tabular}

(a) Média \pm desvio padrão. Letras diferentes significam diferenças estatisticamente significantes $(\mathrm{p}<0,01)$.

Durante o tratamento térmico de alimentos, podese observar tanto a absorção de materiais do meio de processamento, como também a perda de componentes do produto, por evaporação ou por eluição. Tais alterações são produzidas em função do método utilizado, tempo e temperatura de processamento, tamanho, superficie e composição química do alimento [19]. Estudos realizados com diversas espécies de peixes têm sugerido que produtos com menores quantidades de lípides, tendem a absorvê-los do meio durante o processamento [1, $4,9,19]$. Esta poderia ser, portanto, a razão para o significativo aumento do teor lipídico do camarão frito.

\section{2 - Colesterol e 7-cetocolesterol livres}

O colesterol é encontrado no organismo animal e nos alimentos nas formas livre e esterificada. Segundo MASORO [20], em tecidos e fluidos do fígado, córtex adrenal, plasma e linfa de mamíferos a maioria do colesterol está na forma esterificada, enquanto na grande massa muscular esquelética predominantemente se encontra livre. Para a quantificação total em alimentos, torna-se necessária a conversão do colesterol éster em colesterol livre, sendo a saponificação o método mais freqüentemente utilizado neste sentido.

Os processamentos do camarão-rosa fresco, de um modo geral, levaram a uma diminuição nas concentrações de colesterol e 7-cetocolesterol livres (Figuras 2, 3 e 4).

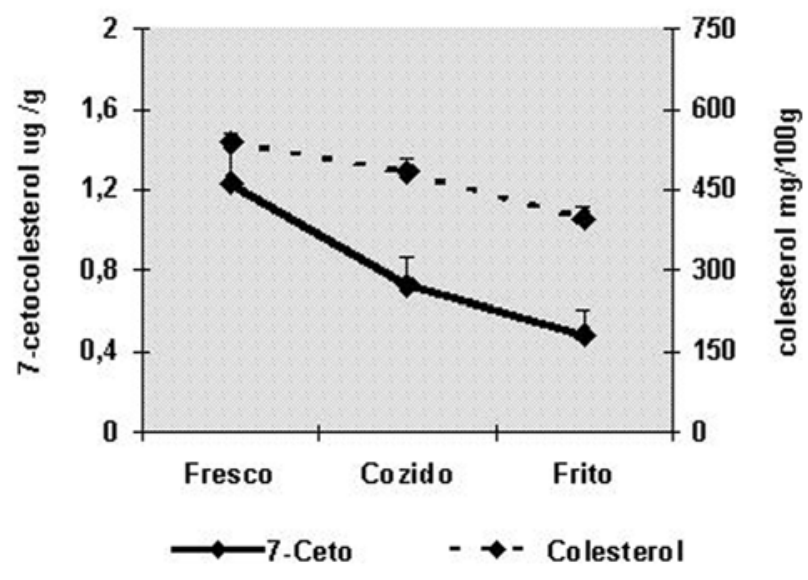

FIGURA 2. Efeito do processamento sobre as concentrações de colesterol e 7-cetocolesterol livres (base seca) em camarão-rosa

A redução das concentrações de colesterol livre só foi significativa $(\mathrm{p}<0,05)$ na fritura (Figura 3). A concen- tração média de colesterol livre no camarão cozido foi $10,7 \%$ menor, enquanto no frito $24,7 \%$. Esta diminuição pode estar relacionada com a oxidação do colesterol, e conseqüente formação de óxidos, e/ou com a sua degradação térmica, e/ou ainda, com sua eluição no óleo de fritura. Por outro lado, não pode ser desconsiderado o fato de que o antioxidante presente no óleo de soja e os antioxidantes naturais do camarão poderiam também exercer alguma proteção sobre o colesterol em relação à oxidação.

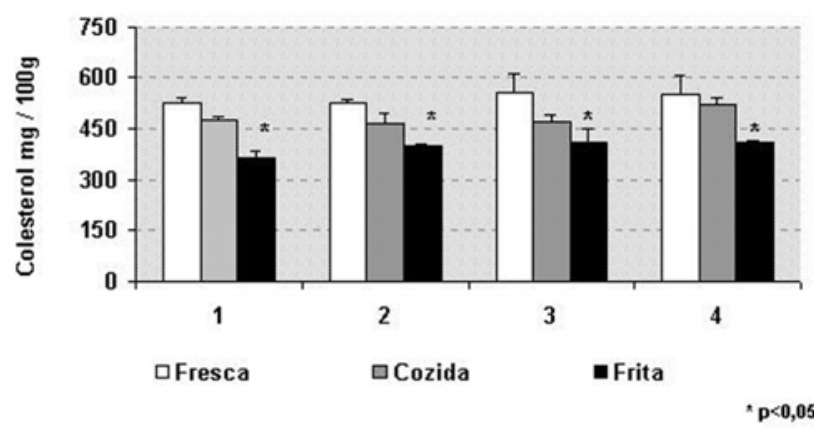

FIGURA 3. Efeito do processamento sobre a concentração de colesterol livre (base seca) em camarão-rosa

A diminuição do colesterol total durante a fritura foi uma observação unânime em estudos que avaliaram o efeito deste processamento. MAI et al. [19] observaram diminuição em filés de peixe grelhados, assados e fritos, mas apenas a fritura atingiu valores significativos. CANDELA, ASTIASARIAN, BELLO [5] verificaram redução entre 15 e $22 \%$ em três espécies de peixes e associaram a perda de colesterol à sua eluição no óleo de fritura. Este fato foi confirmado por WU \& LILLARD [37] que igualmente trabalharam com filés de peixe.

Embora a eluição no óleo de fritura, possa ser a hipótese plausivel para a redução do colesterol em produtos fritos, SANCHEZ-MUNIZ, VIEJO, MEDINA [33], trabalhando com sardinhas, relacionaram-na à absorção do óleo pelo pescado. Desta forma, a concentração de colesterol, ao ser diluída, por um maior conteúdo lipídico do produto, apresentava valores mais baixos. De modo semelhante ao colesterol, as concentrações de 7-cetocolesterol livre diminuíram quando o camarão-rosa foi submetido aos processamentos (Figura 4). Nas amostragens 2 e 3, essa redução foi significativa $(\mathrm{p}<0,001)$ tanto no cozimento quanto na fritura, enquanto nas de números 1 e 4, apenas no camarão frito os valores de 7 -cetocolesterol livre foram reduzidos de forma significativa $(p<0,05)$.

Não foi confirmada a expectativa de que houvesse formação de 7-cetocolesterol, como resultado da oxidação do colesterol, durante os processamentos térmicos do camarão-rosa. O fato dos resultados obtidos sugerirem que durante a cocção e a fritura do camarão-rosa há redução do colesterol e do 7-cetocolesterol é interessante sob o ponto de vista prático.

Os estudos que comprovaram a formação de óxidos de colesterol durante o processamento, geralmente utilizaram períodos prolongados de aquecimento, de 6, 12 
e até 24 horas [26]. Nestes casos, a oxidação ocorreu de maneira gradual, sendo que a formação de óxidos se iniciou dentro das primeiras horas de aquecimento. No presente estudo, o tempo de cozimento e de fritura foram de 4 e 3 minutos, respectivamente, pois o interesse era reproduzir, de forma mais fidedigna possivel, o processamento usual do camarão antes do consumo.

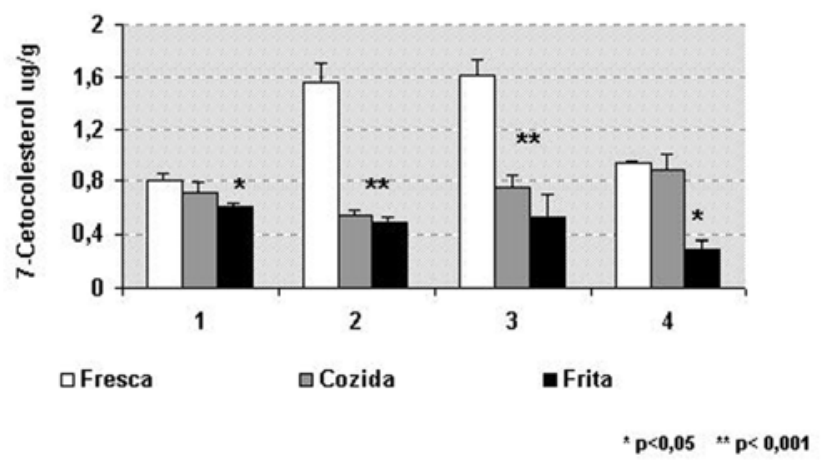

FIGURA 4. Efeito do processamento sobre a concentração de 7-cetocolesterol livre (base seca) em camarão-rosa

DE VORE [7] não observou produção de 7-cetocolesterol durante processamento de carne bovina. RODRIGUEZ-ESTRADA et al. [32] ao submeterem hambúrguer a seis processamentos diferentes também não observaram incremento na concentração de 7-cetocolesterol.

Outros estudos reproduziram o processamento tradicional de alguns alimentos, para avaliação do conteúdo de óxidos de colesterol. Em muitos deles, ao contrário do que foi observado em camarão e em hambúrguer, houve formação de óxidos durante o processamento, mesmo quando o tempo de aquecimento era reduzido. OHSHIMA et al. [23], por exemplo, observaram a formação de óxidos de colesterol entre 3 e 6 minutos de aquecimento, durante a grelhagem de anchovas. Desta forma, observa-se que o tempo de processamento isoladamente, pode não ser decisivo na oxidação do colesterol.

O conteúdo de lípides também possui grande relevância, sendo que a produção de óxidos tem se mostrado sensivelmente menor nos alimentos com baixo teor lipídico [22, 27]. SHOZEN et al. [35] analisaram alguns produtos marinhos tradicionais no Japão e relataram uma forte correlação $\left(r^{2}=0,98\right)$ entre as concentrações de óxidos de colesterol e o conteúdo lipídico dos peixes.

Portanto, imagina-se que, o curto período de aquecimento do camarão-rosa durante os processamentos de cozimento e fritura, associado ao baixo conteúdo lipídico do referido crustáceo, e conseqüentemente à pequena disponibilidade de substrato oxidativo, ainda que altamente insaturado, podem não ter sido suficientes para promover a oxidação do colesterol. Por outro lado, não pode ser desconsiderado o fato de que os antioxidantes naturais do camarão poderiam exercer alguma proteção sobre o colesterol em relação à oxidação.
A fritura aparentemente apresentava maior potencial para oxidação do colesterol porque a temperatura utilizada $\left(140^{\circ} \mathrm{C}\right)$ é mais elevada que no cozimento (cerca de $100^{\circ} \mathrm{C}$ ), aproximando-se da faixa de maior instabilidade do colesterol, 120 a $150^{\circ} \mathrm{C}[14,26]$. No entanto, foi o processamento que levou à maior redução nos níveis de 7 -cetocolesterol livre. Essa redução pode estar relacionada, da mesma forma que o colesterol, à eluição no óleo de fritura. De acordo com a Tabela 2, a eluição destes compostos em óleo foi bem maior que na água utilizada no cozimento, supostamente por uma questão de solubilidade. Os niveis de 7-cetocolesterol observados no óleo de fritura sugerem que a oxidação do colesterol possa ter ocorrido depois de sua eluição no óleo por encontrar neste meio condições satisfatórias para tal, como presença de ácidos graxos polinsaturados e calor. Logo a reutilização deste óleo em outro alimento poderá levar à incorporação dos óxidos formados.

TABELA 2. Concentrações de colesterol e 7-cetocolesterol livres observados na água de cozimento e no óleo de fritura do camarão-rosa.

\begin{tabular}{ccccc}
\hline & Colesterol $\mathrm{mg} / \mathrm{mL}$ & \multicolumn{2}{c}{$\begin{array}{c}\text { 7-Cetocolesterol } \\
\mu \mathrm{g} / \mathrm{mL}\end{array}$} \\
\hline & Mínima & Máxima & Mínima & Máxima \\
\hline Água & 0,003 & 0,029 & 0,060 & 0,160 \\
Óleo & 1,94 & 2,3 & 2,8 & 3,3 \\
\hline
\end{tabular}

\section{4 - CONCLUSÕES}

O processamento de camarão-rosa fresco, nas condições empregadas neste estudo, levaram à redução nas concentrações de colesterol e de 7-cetocolesterol, sendo esta diminuição bem maior na fritura do que no cozimento e mais pronunciada para o 7-cetocolesterol do que para o colesterol.

\section{5 - REFERÊNCIAS BIBLIOGRÁFICAS}

[1] AGREN, J.J., HÄNNINEN, O. Effects of cooking on the fatty acids of three freshwater fish species. Food Chem., v. 46, p. 377-382, 1993.

[2] ASSOCIATION OFFICIAL ANALYTICAL CHEMISTS. Official methods of analysis of the AOAC. 16.ed. Washington: AOAC, 1995. 937p.

[3] BLIGH, E. G., DYER, W.J. A rapid method of total lipid extraction and purification. Can. J. Biochem. Physiol., v. 37, n. 8, p. 911-917, 1959.

[4] CANDELA, M., ASTIASARAN, I., BELLO, J. Effects of frying on the fatty acid profile of some meat dishes. J. Food Compos. Anal., v. 9, p. 277-282, 1996.

[5] CANDELA, M., ASTIASARAN, I., BELLO, J. Effects of frying and warmholding on fatty acids and cholesterol of sole (Solea solea), codfish (Gadus morrhua) and hake (Merluccius merllucius). Food Chem., v. 58, n. 3, p. 227231, 1997.

[6] CSAllanY, A.S., KINDOM, S.E., ADDIS, P. B., LEE, J. HPLC method for quantitation of cholesterol and four of its major oxidation products in muscle and liver tissues. Lipids, v. 24, n. 7, p. 645-651, 1989. 
[7] DE VORE, V. R. TBA values and 7-ketocholesterol in refrigerated raw and cooked ground beef. J. Food Sci., v. 53, n. 4, p. 1058-1061, 1988.

[8] FOLCH, J., LESS, M., STANLEY, S. A simple method for the isolation and purification of the total lipids from animal tissues. J. Biol. Chem., v. 226, p. 497-509, 1957.

[9] GALL, K.L., OTWELL, W.S., KOBURGER, J.A., APPLEDORF, H. Effects of four cooking methods on the proximate, mineral and fatty acid composition of fish fillets. J. Food Sci., v. 48, p. 1068-1074, 1983.

[10] JOHNSTON, J.J., GHANBARI, H.A., WHEELER, W.B., KIRK, J.R. Characterization of shrimp lipids. J. Food Sci., v. 48, p. 33-35, 1983.

[11] KENDALL, C.W., KOO, M., SOKOLOFF, E., KESAVARAO, v. Effects of dietary oxidized cholesterol on azoxymethane-induced colonic preneoplasia in mice. Cancer Lett.,v.66, p. 241-248, 1992.

[12] KESAVA-RAO, V., KOWALE, B.N., BABU, N. P., BISHT, G.S. Effect of cooking and storage on lipid oxidation and development of cholesterol oxidation products in water buffalo meat. Meat Sci., v. 43 , n. 2, p. 179185, 1996.

[13] KIM, S.K., NAWAR, W.W. Oxidative interactions of cholesterol with triacylglycerols. J. Am. Oil Chem. Soc., v. 68, n. 12, p. 931-934, 1991.

[14] KIM, S.K., NAWAR, W.W. Parameters influencing cholesterol oxidation. Lipids, v. 28 , n. 10, p. 917922, 1993.

[15] KING, I., CHILDS, M., DORSSET, C., OSTRANDER, J.G. MONSEN, E.R. Shellfish: proximate composition, minerals, fatty acids and sterols. J. Am. Diet. Assoc., v. 90, n. 5, p. 677-685, 1990.

[16] KRITCHEVSKY, D., TEPPER, S.A., DiTUlLO, N. W., HOLMES, W. The sterols in seafoods. J. Food Sci., v. 32, p. 64-66, 1967.

[17] KRZYNOWEK, J. Sterols and fatty acids in seafood. Food Technol., v. 39, p. 61-68, 1985.

[18] LONG, G.L., WINEFORDNER, J.D. Limit of detection: A closer look at the IUPAC definition. Anal. Chem., v. 55, n. 7, p. 712A-724A, 1983.

[19] MAI, J., SHIMP, J., WEIHRAUCH, J. KINSELLA, J.E. Lipids of fish fillets: changes following cooking by different methods. J. Food Sci., v. 43. p.1669-1674, 1978.

[20] MASORO, E.D. Physiological chemistry of lipids in mammals. Philadelphia: W. B. Saunders Company, 1968. Cap.7, p. 96.

[21] MORGAN, J.N., ARMSTRONG, D.J. Quantification of cholesterol oxidation products in egg yolk powder spraydried with direct heating. J. Food Sci., v. 57, n. 1, p. 4345, 1992.

[22] OHShimA, T., LI, N., KOIZUMI, C. Oxidative decomposition of cholesterol in fish products. J. Am. Oil Chem. Soc., v. 70, n. 6, p. 595-599, 1993.

[23] OHSHIMA, T., SHOZEN, K., USHIO, H., KOIZUMI, C. Effects of grilling on formation of cholesterol oxides in seafoods products rich in polyunsatured fatty acids. Lebensm. Winss. Technol., v. 29, n. 1/2, p. 94-99, 1996.

[24] OHTANI, K., MIYABARA, K., OKAMOTO, E., KAMEI, M., MATSUI-YUASA, I. Cytotoxicity of 7ketocholesterol toward cultured rat hepatocytes and the effec of vitamin E. Biosci. Biotechnol. Biochem., v. 60, n. 12, p. 1989-1993, 1996.
[25] OHTANI, K., TERADA, T., KAMEI, M., MATSUI-YUASA, I. Cytotoxicity of cholestane $3 \beta, 5 \alpha, 6 \beta$-triol on cultured intestinal epithelial crypt cells (IEC-6). Biosci. Biotechnol. Biochem., v. 61, n. 4, p. 573-576, 1997.

[26] OSADA, K., KODAMA, T., YAMADA, K., SUGANO, M. Oxidation of cholesterol by heating. J. Agric. Food Chem., v. 41, p. 1198-1202, 1993a.

[27] OSADA, K., KODAMA, T., CUI, L., YAMADA, K., SUGANO, $M$. Levels and formation of oxidized cholesterol in processed marine foods. J. Agric. Food Chem., v. 41, p. 1893-1898, 1993b.

[28] PANIANGVAiT, P., KING, A.J., JONES, A.D., GERMAN, B.G. Cholesterol oxides in foods of animal origin. A critical review. J. Food Sci., v. 60, n. 6, p. 11591174, 1995.

[29] PENAZZI, G., CABONI, M.F., ZUNIN, P., EVANGELISTI, F., TISCORNIA, E., GALLINATOSCHI, T., LERCKER, G. Routine high performance liquid chromatographic determination of free 7 ketocholesterol in some foods by two different analytical methods. J. Am. Oil Chem. Soc., v. 72, n. 12, p. 1523-1527, 1995.

[30] PENG, S., HU, B., MORIN, R.J. Angiotoxicity and atherogenicity of cholesterol oxides. J. Clin. Labor. Anal., v. 5, p. 144-152, 1991.

[31] PIE, J. E., SPAHIS, K., SEILLAN, C. Cholesterol oxidation in meat products during cooking and frozen storage. J. Agric. Food Chem., v. 39, p. 250-254, 1991.

[32] RODRIGUEZ-ESTRADA, M.T., PENAZZI, G., CABONI, M.F., BERTACCO, G. LERCKER, G. Effect of different cooking methods on some lipid and protein components of hamburgers. Meat Sci., v. 45, n. 3, p. 365-375, 1997.

[33] SÁNCHEZ-MUNIZ, F.J., VIEJO, J.M., MEDINA, R. Deepfrying of sardines in different culinary fats. Changes in the fatty acid composition of sardines and frying fats. $\mathbf{J}$. Agric. Food Chem., v. 40, n. 11, p. 2252-2256, 1992.

[34] SEVANIAN, A., PETERSON, A.R. The cytotoxic and mutagenic properties of cholesterol oxidation products. Food Chem. Toxicol., v. 24, p. 1103-1110, 1986.

[35] SHOZEN, K., OHShiMA, T., USHIO, H., KOIZUMI, C. Formation of cholesterol oxides in marine fish products induced by grilling. Fish. Sci., v. 61, n. 5, p. 817-821, 1995.

[36] SMITH, L.L. Cholesterol autoxidation. Chem. Phys. Lipids, v. 44, p. 87-125, 1987.

[37] WU, W., LILLARD, D.A. Cholesterol and proximate composition of channel catfish (Ictalurus punctatus) fillets - changes following cooking by microwave heating, deepfat frying and oven baking. J. Food Qual., v. 21, p. 41$51,1998$.

[38] ZUNIN, P. Cholesterol oxidation in baked foods containing fresh and powdered eggs. J. Food Sci., v. 60, n. 5, p. 913-916, 1995.

[39] ZUNin, P., EVANGElisti, F., CALCAGNO, C., TISCORNIA, E. Cholesterol oxidation in dried egg pasta: detecting 7-ketocholesterol content. Cereal Chem., v. 73, n. 6, p. 691-694, 1997.

\section{6 - AGRADECIMENTOS}

À CAPES, pela bolsa de estudo concedida, e à FAPESP, pelo auxílio financeiro (Proc. 97/14173-0). 